\title{
Effects of Organic Peroxides on the Curing Behavior of EVA Encapsulant Resin*
}

\author{
Kanthamas Thaworn, Piyapong Buahom, Surat Areerat \\ School of Chemical Engineering, Faculty of Engineering, King Mongkut's Institute of Technology Ladkrabang, Bangkok, Thailand \\ Email: kasurat@kmitl.ac.th
}

Received November 8, 2011; revised March 27, 2012; accepted April 15, 2012

\begin{abstract}
Compounds of poly(ethylene-co-vinyl acetate) (EVA with vinyl acetate content 33\%) with three different organic peroxides, namely, dialkyl peroxide, peroxyester peroxide, and peroxyketal peroxide, were prepared with a twin screws extruder and a two-roll mixing mill. The cure behavior of the EVA compounds was analyzed from rheographs, which were obtained by a moving die rheometer (MDR) at various curing temperatures between $150^{\circ} \mathrm{C}$ to $170^{\circ} \mathrm{C}$. The effects of organic peroxides on cure behavior were examined. The dynamic curing obtained by the torque rheometer provided sufficient experimental data to show that dialkyl peroxide is not suitable because it has a high half-life temperature and its by-products can discolor the final product. Peroxyester peroxide is good for curing at temperatures in the range of $150^{\circ} \mathrm{C}$ to $160^{\circ} \mathrm{C}$, which accomplished an ultimate cure within 5 to 8 minutes. Also, the peroxyketal peroxide has higher performance, which decreased the optimum cure time to 3 minutes. The thermal decomposition mechanism of organic peroxide was applied to explain how the cure behavior is affected by generated free radicals.
\end{abstract}

Keywords: EVA; Encapsulant; Solar Cell; Organic Peroxide; Crosslinking; Dynamic Cure

\section{Introduction}

EVA (ethylene vinyl acetate) are now most commonly used worldwide in a variety of commercial applications, especially as encapsulating materials for solar cell photovoltaic modules, because of its outstanding properties: flexibility, toughness and excellent adhesion on various substrates, high electrical resistivity which makes it as a good electric insulator, low processing and crosslinking temperature, very low water absorption ratio, good optical transmission and high transparency [1,2]. In particular, crosslinking EVA encapsulant resists degradation from weathering better than conventional polyethylene. It is well known that the formulations of EVA-based encapsulant have been developed by Springborn Laboratories, USA [3,4]. The main compositions can be divided into three groups: the EVA resins, curing agents (i.e., organic peroxides) and other additives. The first grade developed was the standard cure grade, which used dialkyl peroxide as the curing agent with a cure time of approximately 25 minutes. The second generation so-called fast cure grade used peroxyester peroxide as the curing agent, with a cure time of 7 minutes. Other additives were a UV absorber, a UV stabilizer, an antioxidant and a silane coupling agent. From the above additive list, it is

${ }^{*}$ Contract grant sponsor: National Research Council of Thailand. implied that the main purpose is to improve the weathering degradation resistance, to which the degree of crosslinking of EVA encapsulant is a key factor. However, crosslinking reactions induced by organic peroxides and silane coupling agent are essential phenomena during the lamination-curing process. Therefore, understanding the cure characteristics is important to improving the quality of encapsulating materials.

Since the rapid growth of commercial solar cell manufacturing in the 1980s, extensive studies have been done [3-9]. A critical review on encapsulation of photovoltaic modules using EVA compounds has been presented by Czanderna and Pern [3]. Wohlgemuth and Peterson [4] reported the long-term result of EVA use as an encapsulant for commercial photovoltaic modules. EVA has proven to be a highly reliable encapsulant. It was insisted that long term efficiency requires well controlled manufacturing of the film itself and the correct lamination procedure to assure adequate cure and bonding to the glass and backsheet surface. Burger and Cuddihy [6] studied the lamination process improvement. The cure cycle used for the lamination process was evacuation for 5 minutes, then 25 minutes of cure. During the 25 minute cure, the first 8 - 10 min was required to raise the encapsulant temperature to $150^{\circ} \mathrm{C}$, where it was maintained until the end of the cycle. Modules were then removed 
without being cooled. Modules fabricated with this cure cycle showed even and complete curing and no bubbles. Galica and Sherman [7] developed faster-curing and flame-retardant EVA-based encapsulant formulations and conducted an improved technique of cure kinetic measurement using a Moving Die Rheometer (MDR), which could reduce cure time determination about $70 \%$ of ordinary technique (standard gel content test).

Several works [10-18] studied peroxide induced crosslinking of EVA. The effects of crosslinking on the thermal and rheological properties of the EVA were studied. One effort to study crosslinking behavior by measuring the torque change was reported by Narkis and Miltz [10]. They applied a Brabender Plastograph to observe initiated crosslinking by increasing the temperature of the mixing rotors while recording torque-time and temperature-curves. The torque difference between the torque applied by the crosslinking mass in the mixing chamber and that applied by the melt prior to the crosslink increased with an increase in the dicumyl peroxide (DCP) content. It is implied that the torque difference can be used to determine a rough criterion for the degree of crosslinking. Mishra et al. [11] studied dynamic crosslinking of EVA/elastomer blends with DCP using a torque rheometer to determine their cure rates and activetion energies. Sung et al. [12] have investigated the effects of crystallinity and crosslinking on the thermal and rheological properties of EVA/DCP compounds using a dynamic mechanical thermal analyzer (DMTA). They found that crosslinking affected the complex viscosities and loss moduli of the compounds. Tai [13] was able to estimate the molecular structure evolution in peroxide induced crosslinking of EVA/DCP using a combination of molecular theory and chemical reaction kinetics such as degree of crosslinking can be predicted efficiently. In the past, crosslinking of EVA had, in most cases, only been initiated by DCP. Recently, modified organic peroxides have been applied to improve the crosslinking efficiency of EVA. Khonakdar et al. [14] have determined the thermal and mechanical properties of crosslinking EVA using 0 - $3 \mathrm{wt} \%$ tert-butylcumyl peroxide (BCUP).

The objective of this study was to examine the effects of organic peroxide on the cure behavior. In order to investigate the effects of organic peroxides on the induction of crosslinking in EVA, the encapsulant samples were cured at constant temperature. During isothermal curing, the thermal decomposition of organic peroxides in encapsulant crosslinking reactions depends on their molecular structures. Three classes of organic peroxide candidates were used: 1) Dialkyl peroxide; 2) Peroxyester peroxide; and 3) Peroxyketal peroxide. Then, their cure behaviors were characterized by MDR. The torquetime cure curves as well as cure time and cure rate were determined.

\section{Experimental}

\subsection{Materials}

EVA, commercialized under the trade name EVAFLEX grade EV-150, [vinyl acetate content $33 \mathrm{wt} \%$, melt flow index (MFI) $30 \mathrm{~g} / 10 \mathrm{~min}$, vicat softening point $33^{\circ} \mathrm{C}$ ], was obtained from the DuPont-Mitsui Chemical Co., Ltd. (Japan). The silane coupling agent was 3-trimethoxysilylpropyl methacrylate from JJ-Degussa Chemical (Thailand) Co., Ltd. The antioxidant was Tris(Nonylphenyl)phosphate, Naugard $P$ from Sigma-Aldrich Co., Ltd. (USA). The UV stabilizer and absorber, obtained from Great Lakes Chemical Corp. (USA), were hindered amine light stabilizer (HALS), bis(2,2,6,6-tetramethyl-4-piperidinyl) sebacate under the trade name Lowilite 77 and Ultraviolet light absorber, 2-Hydroxy-4-octoxybenzophenone under the trade name Lowilite 22, respectively. The three organic peroxides used were supplied by Arkema Pte. Ltd. (Thailand). The basic characteristics of those organic peroxides are given in Table $\mathbf{1}$.

\subsection{Preparation of EVA Compounds}

EVA resins were mixed with organic peroxides, silane coupling agent, and other additives at room temperature. Those additives were dissolved in $20 \mathrm{ml}$ of acetone before being sprayed over the EVA resins. Then, they were compounded by a twin-screw extruder (Plasti-Corder PL2100 model, OHG Duisburg, Germany) with an L/D ratio equal to 16.7 (screw diameter $19.7 \mathrm{~mm}$, die diameter $3 \mathrm{~mm}$ ), screw speed equal to $20 \mathrm{rpm}$, the barrels temperatures equal to $80^{\circ} \mathrm{C}$, and the die temperature equal to $85^{\circ} \mathrm{C}$. Finally, the compounds were sheeted by a two-roll mill at $40^{\circ} \mathrm{C}$ for $5 \mathrm{~min}$. The composition of EVA compounds was presented in Table 2 .

Table 1. Characteristic of organic peroxides [19].

\begin{tabular}{|c|c|c|c|c|c|c|}
\hline \multirow{2}{*}{ Type } & \multirow{2}{*}{ Chemical name } & \multirow{2}{*}{ Trade name } & \multirow{2}{*}{ Assay } & \multirow{2}{*}{ Active Oxygen [\%] } & \multicolumn{2}{|c|}{ Half-life $\left[{ }^{\circ} \mathrm{C}\right]$} \\
\hline & & & & & $10 \mathrm{hr}$. & $1 \mathrm{hr}$ \\
\hline Dialkyl peroxide & Dicumyl peroxide & $D C P$ & $39.5-41.5$ & $2.34-2.46$ & 117 & 137 \\
\hline Peroxyester peroxide & OO-t-Butyl O-(2-Ethylhexyl) monoperoxy-carbonate & Lupersol TBEC & $\geq 95$ & $\geq 6.2$ & 100 & 121 \\
\hline Peroxyketal peroxide & 1,1-Bis-(t-Butylperoxy) 3,3,5-trimethyl-cyclohexane & Lupersol 231 & $\geq 92$ & $\geq 9.73$ & 96 & 115 \\
\hline
\end{tabular}


Table 2. Composition of EVA compounds for crosslinking characteristics test [9].

\begin{tabular}{lc}
\hline Composition & Parts [phr] \\
\hline EVA resin & 100 \\
Organic peroxide & $0.10,0.15,0.20$ \\
UV absorber & 0.30 \\
UV stabilizer & 0.10 \\
Antioxidant & 0.20 \\
Silane coupling agent & 0.25 \\
\hline
\end{tabular}

\subsection{Crosslinking Characteristics Measurement}

The crosslinking characteristics were measured by a Monsanto Moving Die Rheometer (MDR 2000 model, Alpha Technologies, USA) according to the test method ASTM D 5289-97. About $4 \mathrm{~g}$ samples of the respective compounds were tested at temperatures ranging from $150^{\circ} \mathrm{C}$ to $170^{\circ} \mathrm{C}$ with a measuring time of $15 \mathrm{~min}$. The torque-measured data were collected in real time.

\subsection{Determination of Curing Rate}

The crosslinking characteristics were presented by torquetime cure curves. Cure time $\left(t_{\mathrm{C}} 10\right.$ and $\left.t_{\mathrm{C}} 90\right)$ and cure rate index (CRI) were calculated following Equations (1) and (2) respectively.

$$
\begin{aligned}
t_{\mathrm{C}} x & =(x / 100) \cdot\left(\mathrm{M}_{\mathrm{H}}-\mathrm{M}_{\mathrm{L}}\right)+\mathrm{M}_{\mathrm{L}} \\
\mathrm{CRI} & =100 /\left(t_{\mathrm{C}} 90-t_{\mathrm{C}} 10\right)
\end{aligned}
$$

where $\mathrm{M}_{\mathrm{L}}=$ minimum torque $[\mathrm{dNm}]$;

$\mathrm{M}_{\mathrm{H}}=$ maximum torque $[\mathrm{dNm}]$;

$x=$ percent state of cure;

$t_{\mathrm{C}} X=$ time to a given percent $(x)$ state of cure to pro- duce torque.

\section{Results and Discussion}

\subsection{Curing Behavior by Using Dialkyl Peroxide}

Dicumyl peroxide (DCP) is white crystals peroxide. It is commonly used for crosslinking applications. The thermal decomposition of DCP is demonstrated in Scheme 1. As shown in the figure, DCP decomposes to two cumyl radicals. Then, these radicals can undergo a reaction with hydrogen abstraction to produce hydroxylisopropylbenzene (cumyl alcohol) or a beta-scission reaction to produce methyl radicals and acetophenone as a by-product. These methyl radicals have a high energy level of 439.1 $\mathrm{kJ} / \mathrm{mol}$. Peroxides, which generate free radicals $\geq 418.6$ $\mathrm{kJ} / \mathrm{mol}$, possess high crosslinking efficiency due to their ability to abstract secondary hydrogen commonly present in most crosslinkable polymers. The crosslinking mechanism has been described in detail elsewhere [20-23]. Typical decomposition products are methane, acetophenone, and cumyl alcohol. The aromatic by-products or chromophores in the curing step are causes of discoloration in the cured EVA [3]. Discoloration of EVA can reduce PV module efficiency because of decreased light transmittance [9].

The experimental cure curves of EVA-33/Dialkyl peroxide compounds are presented in Figure 1. It shows that cure reaction temperatures of $150^{\circ} \mathrm{C}$ and $160^{\circ} \mathrm{C}$ are not adequate as a marching trend. The plateau curve, as shown at $170^{\circ} \mathrm{C}$, is evidence of sufficient curing. Optimum cure times $\left(t_{\mathrm{C}} 90\right)$ in these cure curves are 23.23, 19.55 and 7.03 minutes, respectively. The cure rate index (CRI) of the curves at $150^{\circ} \mathrm{C}$ and $160^{\circ} \mathrm{C}$ are quite low. However, the CRI of the $170^{\circ} \mathrm{C}$ cure curve is three times greater. For the purposes of productivity, cost reduction, and quality, the lamination-curing processing should be performed at the lowest cure temperature and shortest

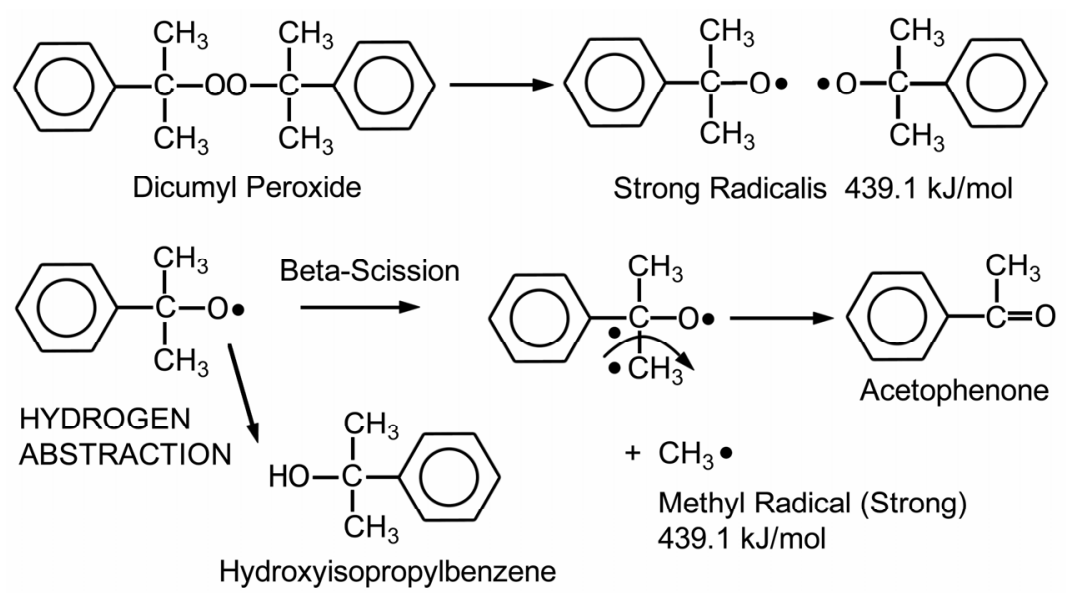

Scheme 1. Thermal decomposition of DCP (Dialkyl peroxide class) [20]. 


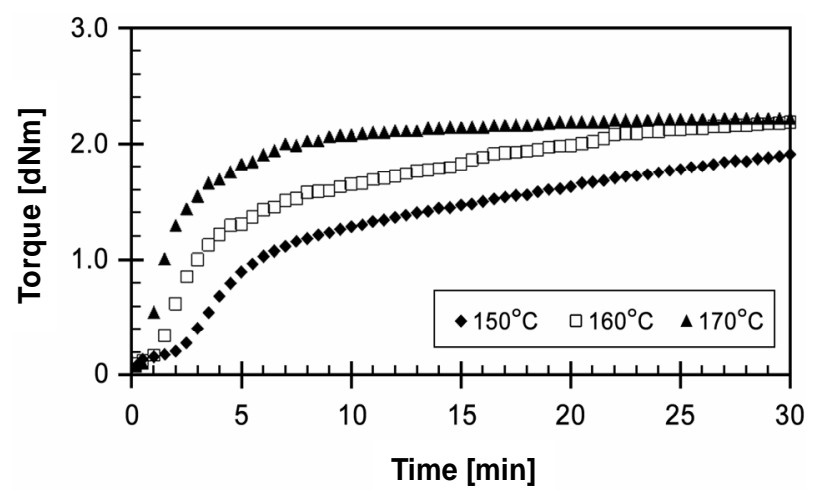

Figure 1. Effect of temperature on cure curves of EVA-33 /Dialkyl peroxide compounds.

cure time. Even though DCP can produce strong free radicals, its half-life temperature is significantly high. Therefore, it takes a long time to decompose at low temperature, or it must be heated up to higher temperature to produce free radicals in a short cure time. Moreover, high cure temperature and/or long cure time can generate acetophenone, which causes yellowing in EVA. It can be seen that using DCP alone is not suitable for EVA-based encapsulant crosslinking, because it requires operating temperatures up to $170^{\circ} \mathrm{C}$ to complete its crosslinking reactions and the final product is light yellowish.

\subsection{Curing Behavior by Using Peroxyester Peroxide}

Lupersol TBEC ${ }^{\text {TM }}$ is a well-known peroxide for fast cure formulation in commercial PV modules. It is pure liquid peroxyester peroxide. This peroxide provides good crosslinking efficiency, and has a high molecular weight of $246 \mathrm{~g} / \mathrm{mol}$. Furthermore, it is non-aromatic, non-discoloring, and does not produce decomposition by-products, which would lead to bloom [19]. Scheme 2 shows the thermal decomposition of Lupersol TBEC. It can generate high energy radicals of $439.5 \mathrm{~kJ} / \mathrm{mol}$. These radical are less stable strong radicals, which can be easily crosslinked [20,22].

The experimental cure curves of EVA-33/Peroxyester peroxide compounds at temperatures of $150^{\circ} \mathrm{C}, 155^{\circ} \mathrm{C}$ and $160^{\circ} \mathrm{C}$ are exhibited in Figure 2. As usual, these cure curves significantly increased up to about 5 minutes and then gradually attained the plateau curve. Also, the maximum torque increased when the cure temperature increased. These compounds showed that this formulation might be used for crosslinking in this temperature range. The optimum cure times $\left(t_{\mathrm{C}} 90\right)$ of these curves are 7.93, 6.63 and 4.52 minutes; the CRI are 14.37, 16.85 and $25.74 \mathrm{~min}^{-1}$, respectively. These results are similar to other reports in literature on fast cure formulation $[7,8]$. Lupersol TBEC has a low half-life temperature $(1 \mathrm{hr}$ halfife at $\left.121^{\circ} \mathrm{C}\right)$. This half-life temperature has a considerable

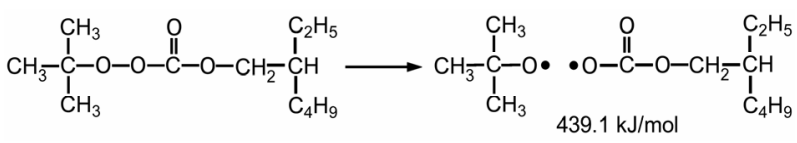

Scheme 2. Thermal decomposition of Lupersol TBEC ${ }^{\text {TM }}$ (Peroxyester peroxide class) [20].

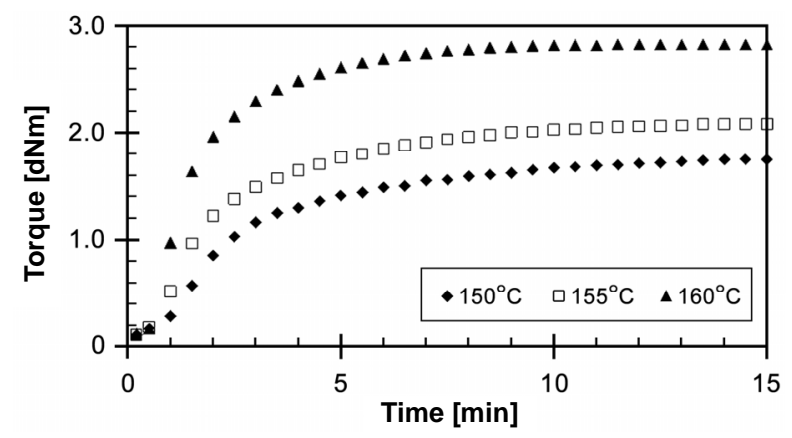

Figure 2. Effect of temperature on cure curves of EVA-33/ Peroxyester peroxide compounds.

effect on the cure performance. Czanderna and Pern [3] recommended the fast cure formulation to the PV industry because the standard cure formulation, which used Lupersol 101, a dialkyl peroxide as a curative, degraded faster than the fast cure formulation under identical accelerated test conditions. Furthermore, they studied the effect of cure temperature and cure time and found that the standardcure increased the concentration of the chromophores as the cure temperature was increased from $130^{\circ} \mathrm{C}$ to $175^{\circ} \mathrm{C}$ for a fixed cure time of 30 minutes, but the fast-cure Lupersol TBEC produced almost no net increase in the chromophores in the same temperature range for a cure time of 15 minutes. In addition, a shorter cure time could reduce the concentration of UV-excitable chromophores that might significantly influence the photothermal stability of EVA [24].

\subsection{Curing Behavior by Using Peroxyketal Peroxide}

The last candidate of peroxide crosslinking systems is peroxyketal peroxide. The peroxyketal peroxide generates a mixture of weak and high energy free radicals, as shown in Scheme 3. The mechanisms of decomposition in peroxyketal peroxides are complex and may vary with specific structures, described in details elsewhere $[19,20]$. This work studied the effect of Lupersol 231 (1 hour half-life at $115^{\circ} \mathrm{C}$ ) on curing behavior, because this peroxide has the lowest half-life temperature and can produce two strong radicals and one weak radical. Thus, Lupersol 231 would be a better choice than peroxyester peroxide for decreasing lamination-curing time. Moreover, the typical decomposition products of Lupersol 231, such as methane, acetone, t-butyl alcohol, and $\mathrm{CO}_{2}$, are non-discoloring $[19,20]$. 

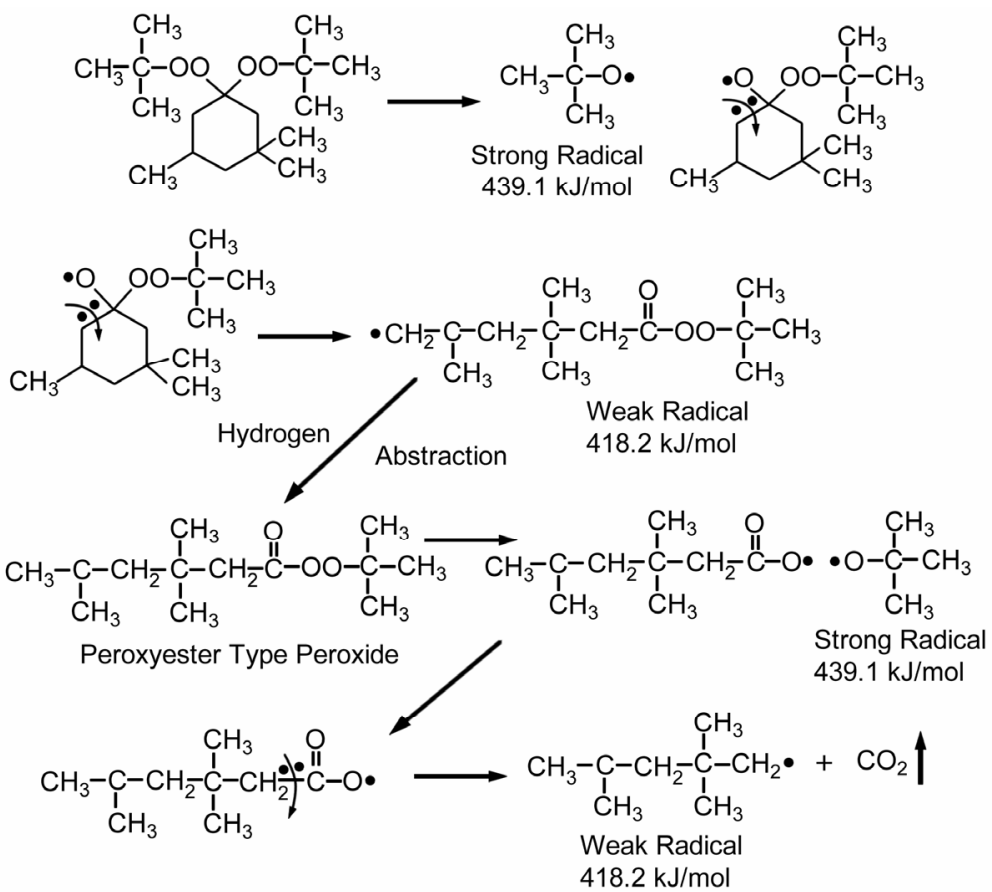

Scheme 3. Thermal decomposition of Lupersol 231 (Peroxyketal peroxide class) [20].

Figure 3 shows the experimentally obtained cure curves of EVA-33/Peroxyketal peroxide compounds at given temperatures of $150^{\circ} \mathrm{C}, 155^{\circ} \mathrm{C}$ and $160^{\circ} \mathrm{C}$ for 15 minutes. It can be seen that the torque dramatically increased and reached the equilibrium state of cure within 3 minutes, while increasing the cure temperature did not significantly affect the maximum torque. Optimum cure times $\left(t_{\mathrm{C}} 90\right)$ of these compounds were $3.15,2.29$ and 1.30 minutes for cure temperatures of $150^{\circ} \mathrm{C}, 155^{\circ} \mathrm{C}$ and $160^{\circ} \mathrm{C}$, respectively. Because the peroxyketal peroxide has a low half-life temperature and because both strong and weak free radicals can occur, it would be extremely active in induced crosslinking reactions.

\subsection{Comparison of Crosslinking Characeristics with Organic Peroxides}

The experimentally obtained curing behaviors of EVA33/Peroxides compounds including cure curve, torque difference, cure time and cure rate index are summarized in this section. Cure curves of three compounds compared with the commercial encapsulant film at given cure temperature $150^{\circ} \mathrm{C}$ and cure time 15 minutes are presented in Figure 4. It can be seen that torque of EVA33/Dialkyl peroxide compound developed the slowest. On the other hand, EVA-33/Peroxyketal peroxide compound can be cured the fastest and most completely. The peroxyketal peroxide can quickly decompose and generate free radicals. It then reacts during the crosslinking reactions that are clearly indicated on its cure curve. EVA$33 /$ Peroxyester peroxide is a bit different from the com- mercial encapsulant film, that is, this compound was cured faster than the commercial encapsulant film. It could be an effect of the other additives used in the formulation,

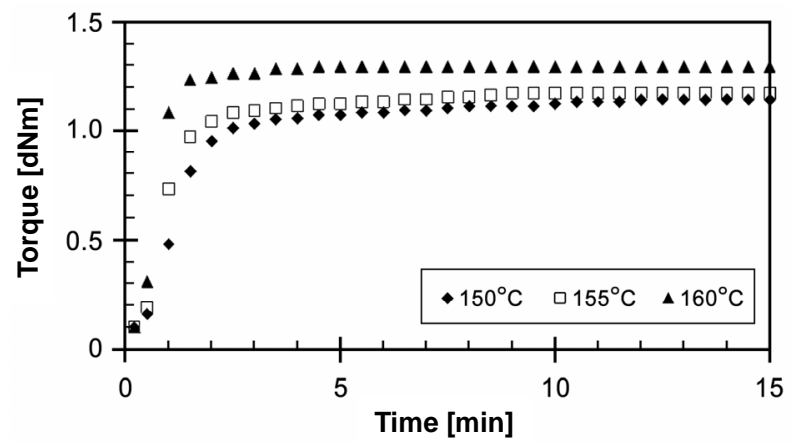

Figure 3. Effect of temperature on cure curves of EVA-33 /Peroxyketal peroxide compounds.

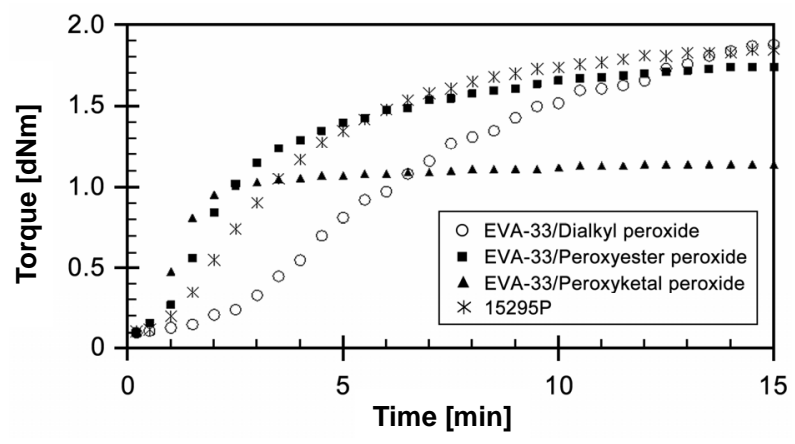

Figure 4. Effect of organic peroxide on cure curves of EVA$33 /$ Peroxides compounds at $150^{\circ} \mathrm{C}$. 
as the recent works have reported that other additives could have a dramatic effect on peroxide cures $[20,25]$. From these experimental cure curves we can conclude that peroxyketal peroxide performs efficiently in EVAbased encapsulants.

In addition to the experimental results from MDR, the torque difference between maximum and minimum torques $\left(\mathrm{M}_{\mathrm{H}}-\mathrm{M}_{\mathrm{L}}\right)$, which is directly related to degree of crosslinking, is shown in Figure 5. It can be seen that torque difference increases with increasing temperature for all types of peroxides. As shown in the cure curves above, rising cure temperature leads peroxides to decompose into radicals faster and for crosslinking reactions to take place spontaneously. Hence, the torques at high cure temperature developed at faster rates, which depend on their half-life temperatures. Besides, the torque difference of EVA-33/Peroxyester peroxide compound extends significantly more with cure temperature than those of other compounds.

The cure times required to reach $90 \%$ of the cured state $\left(t_{\mathrm{C}} 90\right)$ in these compounds are compared in Figure 9. It can be seen that cure time decreases with increasing temperature. EVA-33/Dialkyl peroxide has a slow cure time of up to 20 minutes for $150^{\circ} \mathrm{C}$ and $160^{\circ} \mathrm{C}$, which then dramatically decreases 3 times to 7 minutes at a curing temperature of $170^{\circ} \mathrm{C}$. EVA-33/Peroxyester peroxide and EVA-33/Peroxyketal peroxide compounds clearly had fast cure times. Figure 6 revealed that peroxyketal peroxide can be cured faster than peroxyester peroxide: about 2.5 times as fast at the same cure temperature of $150^{\circ} \mathrm{C}$ and about 4 times as fast by increasing the cure temperature $10^{\circ} \mathrm{C}$. Thus, it would be possible to use peroxyketal peroxide at cure temperatures lower than $150^{\circ} \mathrm{C}$ in order to avoid any thermal degradation, while the present commercial encapsulant cannot attain the same cure level below $150^{\circ} \mathrm{C}$. This is emphasized in Figure 7, which displays the cure rate index (CRI) of those compounds. In addition, the efficiency of dialkyl peroxide

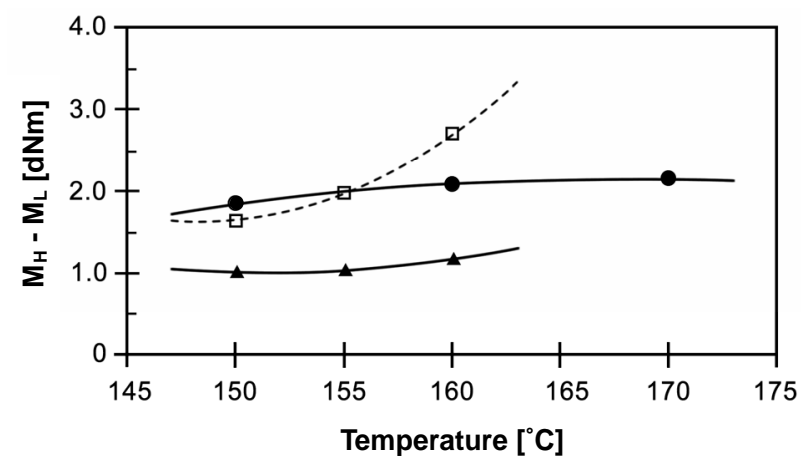

Figure 5. Effect of temperature on torque difference $\left(\mathrm{M}_{\mathbf{H}}\right.$ $M_{L}$ ) of EVA-33/Peroxides compounds. (O) EVA-33/Dialkyl peroxide; ( $\square$ ) EVA-33/Peroxyester peroxide; (A) EVA-33/ Peroxyketal peroxide.

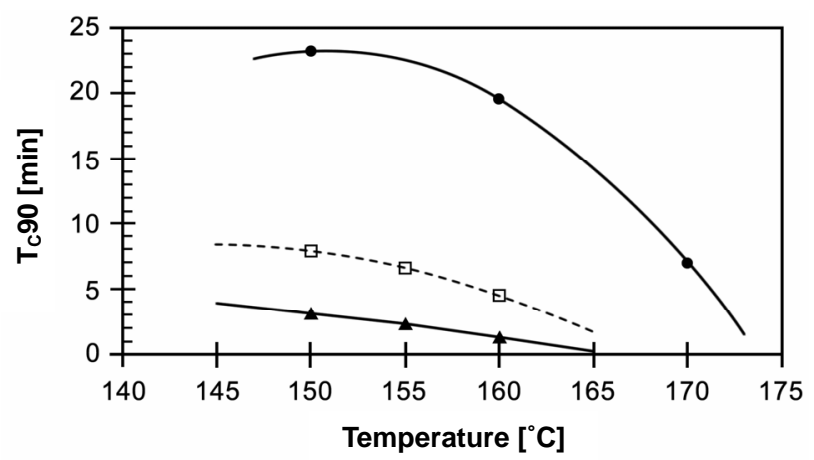

Figure 6. Effect of curing temperature on $t_{c} 90$ of EVA-33 /Peroxides compounds. (O) EVA-33/Dialkyl peroxide; ( $\square$ ) EVA-33/Peroxyester peroxide; (A) EVA-33/Peroxyketal peroxide.

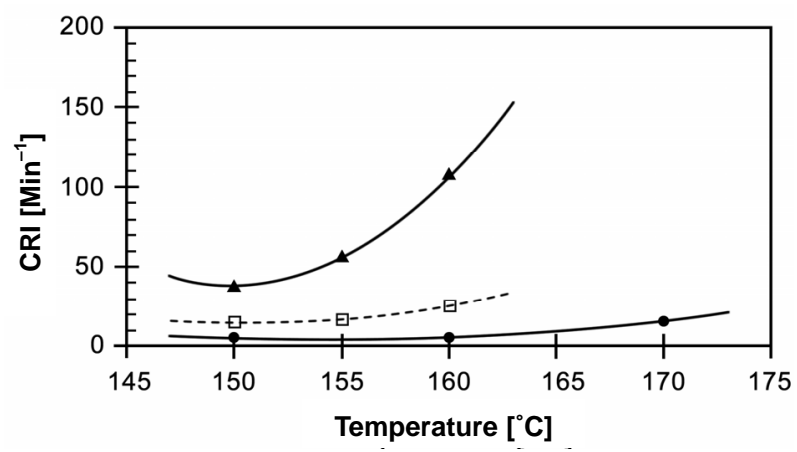

Figure 7. Effect of curing temperature on cure rate index (CRI) of EVA-33/Peroxides compounds. (O) EVA-33/ Dialkyl peroxide; ( $\square$ ) EVA-33/Peroxyester peroxide; (A) EVA-33/ Peroxyketal peroxide.

at $170^{\circ} \mathrm{C}$ is approximately equal to peroxyester peroxide at $150^{\circ} \mathrm{C}$.

The lamination-curing process using a vacuum laminator can be divided into 2 processes: lamination and curing. Specific processing conditions (i.e., time, temperature, and pressure) are not readily known because they are considered proprietary information by PV manufacturers [26]. Nevertheless, solar cell and other assembly parts are generally put into the laminator chamber. Then, the lamination process is operated, the EVA film is melted, spread covered on the solar cells, and then selfbonded to the cover glass and backing materials. The lamination temperature is generally not over $120^{\circ} \mathrm{C}$. In this step, thermal decomposition of organic peroxide must be avoided because the peroxide, such as Lupersol TBEC (peroxyester peroxide), has a tendency to generate bubbles from $\mathrm{CO}_{2}$ and other gaseous organics. Moreover, prior industry experience emphasized that increasing lamination temperatures is unfeasible at temperature approaching $155^{\circ} \mathrm{C}$. Thus, temperature control, information on the thermal decomposition of organic peroxide and operator skill are required for PV manufacturers to pre- 
vent bubble formation [4]. In the curing process, the temperature is increased up to $150^{\circ} \mathrm{C}$ to $160^{\circ} \mathrm{C}$ (general curing temperature) and the crosslinking reactions can be accomplished in 7 minutes at $150^{\circ} \mathrm{C}$ (for commercial grade).

Wohlgemuth and Shea [8] reported that curing temperature had an influence on peroxide decomposition products from the IR analysis of the thermal effluents from EVA encapsulants. That analysis concluded that water evolved at $105^{\circ} \mathrm{C}, \mathrm{CO}_{2}$ at $120^{\circ} \mathrm{C}$, acetone and t-butanol at $177^{\circ} \mathrm{C}$ and acetic acid at $205^{\circ} \mathrm{C}$. It was further determined that at least $1.5 \mathrm{wt} \%$ water could be present in a $33 \mathrm{wt} \%$ VA containing EVA following short exposure to air. They suggested that completely dried EVA encapsulants under vacuum for 18 hours at $50^{\circ} \mathrm{C}$ had no bubbles formation during the lamination process.

Therefore, the use of peroxyketal peroxide as a curative in EVA-based encapsulant formulation is an interesting and possible choice for new formulations. This peroxide has a low half-life temperature and non-discoloring by-products. EVA/Peroxyketal peroxide formulation can be produced by film extrusion and pre-dried before use in the lamination process. This film would be used under low cure temperature and time conditions. The combination of these factors could prevent bubble formation and obtain a good yield of crosslinked EVA.

\subsection{Effect of Organic Peroxide Concentrations on Curing Behaviors}

Typically peroxide concentrations ranging from 0.5 to 2.0 parts by weight per one hundred parts of resin (phr) are recommended [19]. At lower concentrations, the curing process may be slow and physical property deterioration may be encountered. Higher peroxide concentrations are not cost effective since initiator is lost in wasteful side reactions. Thus, in this work the effect of peroxide concentration ranging from 0.10 to $0.2 \mathrm{phr}$ was determined.

EVA-33/Peroxyester peroxide compounds of different concentrations were cured at a cure temperature of $150^{\circ} \mathrm{C}$ for $15 \mathrm{~min}$, as shown in Figure 8. At the start of curing, there are no differences in their cure curves. After 1 minute of curing, it can be seen that the torques of 0.10 and $0.15 \mathrm{phr}$ increase and attain the optimum cure; moreover, the concentration of $0.10 \mathrm{phr}$ can be cured faster than the concentration $0.15 \mathrm{phr}$. The result is clear; $0.10 \mathrm{phr}$ has fewer free radicals to initiate the crosslinking reactions. On the other hand, a concentration $0.20 \mathrm{phr}$ showed the marching trend with the maximum torque $\left(\mathrm{M}_{\mathrm{H}}\right)$ higher than the others. This implies that this concentration may generate an excess of free radicals, which allows the crosslinking reaction to take place much more than at other concentrations. The 15 minutes cure time may be not efficient to reach the optimum cure. Optimum cure times $\left(t_{C} 90\right)$ of these cures were $7.20,7.93$ and 8.73 minutes respectively. The CRI decreased with increasing peroxide concentration.

Figure 9 presents experimental cure curves of EVA$33 /$ Peroxyketal peroxide $(0.10,0.15$ and $0.20 \mathrm{phr}$ ) compounds at a given cure temperature of $150^{\circ} \mathrm{C}$ for a cure time of 15 minutes. It is quite similar to EVA-33/ Peroxyketal peroxide compounds. All concentration compounds could be completely cured. Optimum cure time $\left(t_{\mathrm{C}} 90\right)$ of 0.10 and $0.15 \mathrm{phr}$ cure curves were 3.05 and 3.15 minutes, but at $0.20 \mathrm{phr}$ it was up to 4.28 minutes. The CRI of the $0.20 \mathrm{phr}$ was lower than the 0.10 and 0.15 phr approximately $33 \%$.

\section{Conclusions}

The curing behavior of organic peroxides induced crosslinking EVA compounds were studied using a moving die rheometer (MDR), which is suitable for real-time isothermal crosslinking reaction study. Three classes of organic peroxide candidates were studied: 1) Dialkyl peroxide; 2) Peroxyester peroxide; and 3) Peroxyketal peroxide. From the cure characteristics, we observed that thermal decomposition of organic peroxide via free radical generation obviously affects the cure rates of the compounds. It can be concluded that dialkyl peroxide is

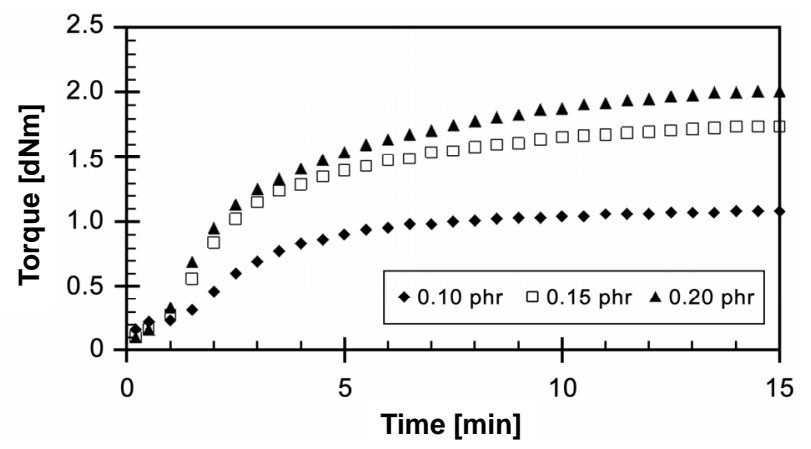

Figure 8. Effect of peroxide concentration on cure curves of EVA-33/Peroxyester peroxide compounds at cure temperature $150^{\circ} \mathrm{C}$.

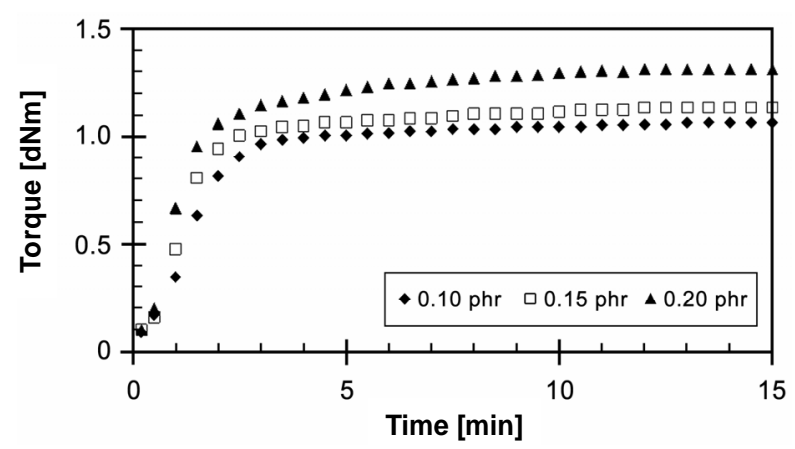

Figure 9. Effect of peroxide concentration on cure curves of EVA-33/Peroxyketal peroxide compounds at cure temperature $150^{\circ} \mathrm{C}$. 
not suitable because it has a high half-life temperature and its by-products can discolor the final product. Peroxyester peroxide is good for curing at temperatures in the range of $150^{\circ} \mathrm{C}$ to $160^{\circ} \mathrm{C}$, which accomplished ultimate cure within 5 to 8 minutes. Moreover, peroxyketal peroxide has higher performance, which decreased optimum cure time to 3 minutes. For the effect of peroxide concentration ranging between 0.1 and $0.2 \mathrm{phr}$, we found that the cure rate index (CRI) decreased with increasing peroxide concentration.

In terms of crosslinking reaction via free radical chemistry, after decomposition of peroxide initiator took place. Two competitive reaction pathways are of importance: 1) Direct polymer main chain crosslinking, via free radical of peroxide initiator; and 2) Grafting of silane onto the polymer backbone, via initiation of a peroxide free radical. These reaction classes will yield different product slates, as they are dominated by homolytic and heterolytic pathways, respectively. Control over the activity of the different peroxides (via active oxygen content and decomposition temperature) may provide control over the relative importance of these different pathways, and product selectivity. Therefore, this work leaves a couple of issues on the reaction fundamentals to be resolved, including: 1) The possible interaction between different peroxides with silane and UV additives; 2) The effect of added different peroxides on adhesion to glass and long term UV stability of the solar cell module. In the practical sense, the experimental results are encouraging as using newly developed peroxide derivative may be benefit to the solar cell manufacturers.

\section{Acknowledgements}

Financial support from the National Research Council of Thailand (grant code: 500-1110-5240-26) is gratefully acknowledged. The authors also acknowledge the participation of industrial partners: Bangkok Solar Co. Ltd., for commercial encapsulant samples as well as technical visitation and useful information and Arkema (Thailand) Pte. Ltd. The Polymer Science Program, Faculty of Science, Prince of Songkha University is thanked for providing the MDR instrument.

\section{REFERENCES}

[1] P. Galli and G. Vecellio, "Polyolefins: The Most Promising Large-Volume Materials for the 21st Century," Journal of Polymer Science Part A: Polymer Chemistry, Vol. 42, No. 3, 2004, pp. 396-415. doi:10.1002/pola.10804

[2] A. El Amrani, A. Mahrane, F. Y. Moussa and Y. Boukennous, "Solar Module Fabrication," International Journal of Photoenergy, Vol. 2007, Article ID 27610. doi: $10.1155 / 2007 / 27610$

[3] A. W. Czanderna and F. J. Pern, "Encapsulation of PV
Modules Using Ethylene Vinyl Acetate Copolymer as a Pottant: A Critical Review," Solar Energy Materials and Solar Cells, Vol. 43, No. 2, 1996, pp. 101-181. doi:10.1016/0927-0248(95)00150-6

[4] J. H. Wohlgemuth and R. C. Petersen, "Solarex Experience with Ethylene Vinyl Acetate Encapsulation," Solar Cells, Vol. 30, No. 1, 1991, pp. 383-387. doi:10.1016/0379-6787(91)90071-V

[5] K. J. Lewis, "Encapsulant Material Requirements for Photovoltaic Modules," In: C. G. Geblein, D. J. Williams and R. D. Deanin, Eds., Polymers in Solar Energy Utilisation, American Chemical Society (ACS), Washington DC, 1983, pp. 367-385. doi:10.1021/bk-1983-0220.ch023

[6] E. F. Cuddihy, D. R. Burger, P. Willis, B. Baum, A. Garcia and C. Minning, "Polymer Encapsulation Materials for Low-Cost Terrestrial Photovoltaic Modules," In: C. G. Geblein, D. J. Williams and R. D. Deanin, Eds., Polymers in Solar Energy Utilisation, American Chemical Society (ACS), Washington DC, 1983, pp. 353-366. doi:10.1021/bk-1983-0220.ch022

[7] J. P. Galica and N. Sherman, "Results to Date-Development of New EVA-Based Encapsulants, Faster-Curing and Flame Retardant Types," Conference Record of the 28th IEEE Photovoltaic Specialists Conference, Anchorage, 15-22 September 2000, pp. 30-35. doi:10.1109/PVSC.2000.915746

[8] S. P. Shea and J. H. Wohlgemuth, "Improvements to Polycrystalline Silicon PV Module Manufacturing Technology," Conference Record of the 29th IEEE Photovoltaic Specialists Conference, New Orleans, 19-24 May 2002, pp. 227-230. doi:10.1109/PVSC.2002.1190497

[9] P. Klemchuk, M. Ezrin, G. Lavigne, W. Holley, J. Galica and S. Agro, "Investigation of the Degradation and Stabilization of EVA-Based Encapsulant in Field-Aged Solar Energy Modules," Polymer Degradation and Stability, Vol. 55, No. 3, 1997, p. 347. doi:10.1016/S0141-3910(96)00162-0

[10] M. Narkis and J. Miltz, "Peroxide Crosslinking of Ethylene-Vinyl Acetate Copolymer," Journal of Applied Polymer Science, Vol. 21, No. 3, 1977, pp. 703-709. doi:10.1002/app.1977.070210311

[11] S. Mishra, B. Baweja and R. Chandra, "Studies on Dynamic and Static Crosslinking of Ethylene Vinyl Acetate and Ethylene Propylene Diene Tercopolymer Blends," Journal of Applied Polymer Science, Vol. 74, No. 11, 1999, pp. 2756-2763. doi:10.1002/(SICI)1097-4628(19991209)74:11<2756::AI D-APP23>3.0.CO;2-I

[12] Y. T. Sung, C. K. Kum, H. S. Lee, J. S. Kim, H. G. Yoon and W. N. Kim, "Effect of Viscosity Ratio and Acetate Copolymer," Polymer, Vol. 46, No. 25, 2005, pp. 11844 11848. doi:10.1016/j.polymer.2005.09.080

[13] H. J. Tai, "Molecular Structure Evolution in PeroxideInitiated Crosslinking of an Ethylene Vinyl Acetate Copolymer and a Metallocene Polyolefin Elastomer," Polymer Engineering \& Science, Vol. 39, No. 9, 1999, pp. 1577-1583. doi:10.1002/pen.11551

[14] H. A. Khonakdar, S. H. Jafari, A. Haghighi-Asl, U. Wagenknecht, L. Haussler and U. Reuter, "Thermal and 
Mechanical Properties of Uncrosslinked and Chemically Crosslinked Polyethylene/Ethylene Vinyl Acetate Copolymer Blends," Journal of Applied Polymer Science, Vol. 103, No. 5, 2007, pp. 3261-3270. doi:10.1002/app.25268

[15] A. Thitithammawong, C. Nakason, K. Sahakaro and J. Noordermeer, "Effect of Different Types of Peroxides on Rheological, Mechanical, and Morphological Properties of Thermoplastic Vulcanizates Based on Natural Rubber/ Polypropylene Blends," Polymer Testing, Vol. 26, No. 4, 2007, pp. 537-546.

doi:10.1016/j.polymertesting.2007.02.002

[16] T. Fargere, M. Abdennadher, M. Delmas and B. Boutevin, "Determination of Peroxides and Hydroperoxides with 2,2-diphenyl-1-picrylhydrazyl (DPPH), Application to Ozonized Ethylene Vinyl Acetate Copolymers (EVA)," European Polymer Journal, Vol. 31, No. 5, 1995, pp. 489-497. doi:10.1016/0014-3057(94)00201-0

[17] J. S. Parent, K. Geramita, S. Ranganathan and R. A. Whitney, "Silane-Modified Poly(ethylene-co-vinyl acetate): Influence of Comonomers on Peroxide-Initiated Vinylsilane Grafting," Journal of Applied Polymer Science, Vol. 76, No. 8, 2000, pp. 1308-1314. doi:10.1002/(SICI)1097-4628(20000523)76:8\%3c1308:: AID-APP11\%3e3.0.CO;2-7

[18] J. S. Parent, M. Spencer and R. A. Whitney, "Influence of Hydrogen Donors on Peroxide-Initiated Melt Grafting of Vinylsilane to Poly(ethylene-co-vinyl acetate)," Journal of Applied Polymer Science, Vol. 83, No. 11, 2002, pp. 2397-2402. doi:10.1002/app.10304

[19] Arkema Inc., "Product Bulletin, Organic Peroxides: General Catalog," 2006.
[20] J. S. Dick, R. A. Annicelli, C. Baddorf, K. Baranwal and C. J. Cable, "Rubber Technology: Compounding and Testing for Performance," 2nd Edition, Hanser Gardner Publications, Ohio, 2009.

[21] O. Bianchi, J. De N. Martins, R. Fiorio, R. V. B. Oliveira and L. B. Canto, "Changes in Activation Energy and Kinetic Mechanism during EVA Crosslinking," Polymer Testing, Vol. 30, No. 6, 2011, pp. 616-624. doi:10.1016/ j.polymertesting.2011.05.001

[22] P. A. Callais, "Organic Peroxides," In: A. Tracton, Ed., Coating Technology Handbook, 3rd Edition, CRC Press, Boca Raton, 2006.

[23] M. M. A. Grima, "Novel Co-Agents for Improved Properties in Peroxide Cure of Saturated Elastomers," Ph.D. Thesis, University of Twente, Enschede, 2007.

[24] F. J. Pern, "Factors That Affect the Eva Encapsulant Discoloration Rate upon Accelerated Exposure," Solar Energy Materials and Solar Cells, Vol. 41-42, 1996, pp. 587-615. doi:10.1016/0927-0248(95)00128-X

[25] Y.-F. Lin, C.-P. Lin, L.-Y. Chen, T.-S. Su, J.-M. Tseng, "Effect of Different Concentrations of Acetone for the Decomposition Reactions of Peroxyketal Peroxides," Thermochimica Acta, Vol. 527, 2012, pp. 27-32. doi:10.1016/j.tca.2011.09.026

[26] F. J. Pern and S. H. Glick, "Thermal Processing of EVA Encapsulants and Effects of Formulation Additives (for Solar Cells)," Conference Record of the 25th IEEE Photovoltaic Specialists Conference, Washington DC, 13-17 May 1996, pp. 1251-1254. doi:10.1109/PVSC.1996.564359 